\title{
Concordance rates of Wilson's disease phenotype among siblings
}

\author{
Grzegorz Chabik • Tomasz Litwin • Anna Czlonkowska
}

Received: 21 February 2013 /Revised: 17 May 2013 / Accepted: 27 May 2013 /Published online: 18 June 2013

(C) The Author(s) 2013. This article is published with open access at Springerlink.com

\begin{abstract}
Wilson's disease (WD) is an autosomal recessive disorder characterized by the functional disruption of adenosine triphosphatase 7B (ATP7B), which results in positive copper balance. Although the primary manifestations of the disease are hepatic or neurological in scope, the factors that cause a very diverse picture of WD are not well researched. We compared the first clinical presentation, ages of onset and diagnosis, copper metabolism parameters, and ceruloplasmin levels between index cases (ICs) and their siblings. We examined 73 ICs and 95 siblings from 73 families, including a total of 168 patients with biochemical and genetically confirmed WD diagnoses. We observed an $86 \%$ concordance rate of primary clinical symptoms among ICs with hepatic symptoms and their siblings. There was $66 \%$ concordance among ICs with neurological symptoms and their siblings. No differences regarding age at onset of symptoms or copper metabolism parameters at diagnosis were identified between hepatic ICs and their siblings. The age at symptom onset did not differ between neurological ICs and their siblings, although ICs presented lower ceruloplasmin and serum copper levels. These results demonstrate a high intrafamilial concordance of the clinical and biochemical presentation of $\mathrm{WD}$, suggesting that similar factors shared within the same families strongly influence the disease presentation.
\end{abstract}

\section{Introduction}

Wilson's disease (WD, OMIM: 277900), also referred to as hepatolenticular degeneration, is a systemic disorder of

Communicated by: Ertan Mayatepek

The research approval number: 06/2006, Bioethical Committee seated at Institute of Psychiatry and Neurology, 9 Sobieskiego Str., 02- 957 Warsaw, Poland.

G. Chabik $\cdot$ T. Litwin $\cdot$ A. Członkowska $(\bowtie)$

2nd Department of Neurology, Institute of Psychiatry and

Neurology, 9 Sobieskiego Str., 02-957 Warsaw, Poland

e-mail: czlonkow@ipin.edu.pl copper metabolism with an autosomal recessive mode of inheritance. Hepatic or neurological symptoms are the primary manifestations. The estimated prevalence of WD is 1 in 7000 to 1 in 100,000, and gene carrier frequency is estimated at more than 1 in 90 (Scheinberg and Sternlieb 1984; Olsson et al 2000; Coffey et al 2013). Most patients develop initial symptoms during the second and third decades of life.

The gene responsible for WD is located on chromosome 13, band q14.3 (13q14.3-q21.1). This gene encodes a membrane-bound, copper-transporting P-type ATPase (ATP7B, OMIM: 606882) that is crucial for the excretion of copper by hepatocytes and its binding to ceruloplasmin. Thus far, approximately 500 mutations of APT7B have been identified. No direct genotype-phenotype correlation has been proven regarding $\mathrm{WD}$, as the data published to date have shown somewhat conflicting results (Houwen et al 1995; Ha-Hao et al 1998; Stapelbroek et al 2004; Vrabelova et al 2005; Gromadzka et al 2006). However, one consistent finding suggests that patients with severe mutations (e.g., frameshift and nonsense mutations) present earlier onset of the disease and more severe metabolic disturbances than patients with missense mutations (Gromadzka et al 2005). It is also clear that patients with the same mutations can display different phenotypes (Deguti et al 2004; Gupta et al 2007). Therefore, it seems reasonable to assume that other compound genetic interactions (other than APT7B mutation), as well as epigenetic and environmental factors, may play an important role in disease presentation (Deguti et al 2004; Das and Ray 2006; Gupta et al 2007; Behari and Pardasani 2010; Litwin and Członkowska 2013).

To capture more precisely the influence of such factors, it is reasonable to compare the clinical presentation of WD among siblings from the same families, rather than in an unrelated patient cohort (Santhosh et al 2008). Data from published familial studies has been somewhat limited and based on small numbers of cases, with inconsistent results (Takeshita et al 2002; Vrabelova et al 2005; Santhosh et al 2008). It appears that even monozygotic twins can display 
completely different symptom patterns and ages of onset (Członkowska et al 2009).

The aim of the present study was to evaluate the concordance rate and compare the initial clinical and biochemical manifestations of WD among 168 siblings from 73 separate families.

\section{Materials and methods}

\section{Subjects}

After obtaining approval from the bioethical committee, index cases (ICs) and their siblings with a confirmed diagnosis of WD and full clinical information (described below) were identified from our registry of 609 patients. All of them underwent clinical investigation and received a diagnosis of WD at the Institute of Psychiatry and Neurology in Warsaw. Diagnosis was based on clinical features, the presence of Kayser-Fleischer rings, serum ceruloplasmin and copper levels, and 24-h urine copper concentration. In most cases, DNA analysis was performed and APT7B mutations were identified according to the method described below.

The following data were included in the analysis:

- age at symptoms onset (first clinical signs strongly suggestive of WD in symptomatic patients)

- clinical signs at onset: hepatic or neurological

- age at diagnosis

- biochemical parameters at diagnosis, including serum ceruloplasmin, serum copper, and copper concentration in a 24-h urine sample

- mutation status of the carrier

All ICs were divided into two main groups based on their initial predominant symptoms of WD (i.e., hepatic or neurological) according to the phenotypic classification of Wilson's disease proposed by Ferenci et al in 2003. Siblings were similarly grouped or recognized as presymptomatic (i.e., without signs, symptoms, or laboratory findings suggestive of WD) prior to diagnosis. Hepatic signs and symptoms included abdominal pain, jaundice, ascites, acute/chronic liver failure, hemostatic disturbance, history of hemolytic anemia, and abnormal liver tests. Neurological signs and symptoms included tremor, dystonia, speech, facial expression, gait disturbances, and ataxia, as well as neuropsychiatric disturbances like mood, emotional and behavioral control imbalance, and frank psychosis.

Dividing main groups of patients into subgroups according to the mutation status of the ICs and siblings resulted in patient populations that were too small for genotype-phenotype analysis. Therefore, only basic genetic data was analyzed by subgroup.
Laboratory examinations

Serum ceruloplasmin levels were measured using the improved colorimetric enzymatic assay developed by Ravin (1961). Serum copper concentration and 24-h urinary copper excretion were measured using flame atomic absorption spectrometry (FAAS). ATP7B genotyping was performed using polymerase chain reaction restriction fragment length polymorphism analysis and/or direct ATP7B gene sequencing, as described previously (Gromadzka et al 2005, 2006).

\section{Statistics}

Variables are reported as means and $95 \%$ confidence intervals (95\% CIs), and were compared between groups using the Mann Whitney U test, analyzed with SPSS Statistics 17.0 software. Values of $p<0.05$ were considered statistically significant.

\section{Between-group comparison}

To calculate the concordance rate, we employed the proband- or case-wise concordance rate, judging the proportion of individuals with the same trait — here, the first disease manifestation among ICs and their siblings (Smith 1974). The following formula was used in this estimation: Casewise concordance $(\mathrm{Cc})=2 \mathrm{C} /(2 \mathrm{C}+\mathrm{D})$, where $\mathrm{C}$ is the number of concordant siblings and $\mathrm{D}$ is the number of discordant pairs (McGue 1992).

\section{Results}

We identified 73 ICs with 95 siblings for analysis. Among ICs, 30 patients ( $41 \%$ ) exhibited predominantly hepatic WD and $43(59 \%)$ exhibited predominantly neurological WD symptoms at onset.

In the group of 30 ICs with hepatic presentation at onset, there were 21 ICs with 24 siblings that were also symptomatic: 18 (75\%) had hepatic signs and symptoms, six (25\%) had neurological initial manifestation of the disease, and 11 were presymptomatic. Therefore, according to the employed formula (see Methods), there was an $86 \%$ rate of concordance of initial signs and symptoms at onset in this group. We observed no significant differences between hepatic ICs and their respective symptomatic siblings regarding age at onset, age at diagnosis, ceruloplasmin level, serum copper concentration, or 24-h urine copper concentration. We also observed no differences between the hepatic ICs and any of their symptomatic or presymptomatic siblings regarding age at diagnosis, ceruloplasmin and serum copper levels, or 24-h urine copper concentration (Table 1). 
Table 1 Clinical and biochemical characteristics of index cases (ICs) with hepatic signs at onset and their siblings

\begin{tabular}{llllll}
\hline Group & All hepatic ICs & All siblings of hepatic ICs & Hepatic siblings & $\begin{array}{l}\text { Neurological } \\
\text { siblings }\end{array}$ & $\begin{array}{l}\text { Presymptomatic } \\
\text { siblings }\end{array}$ \\
\hline $\mathrm{N}$ & 30 & 35 & 18 & 6 & 11 \\
Age at onset, years & $23.1(19.7-26.5)$ & $\mathrm{NA}$ & $24.2(17.8-30.5)$ & $25.7(16.5-34.8)$ & $\mathrm{NA}$ \\
Age at diagnosis, years & $25.2(21.7-28.6)$ & $26.0(22.3-29.8)$ & $27.6(21.5-30.6)$ & $28.7(19.4-37.9)$ & $22.0(17.1-26.8)$ \\
Ceruloplasmin, mg/dl & $11.7(9.4-14.1)$ & $11.5(9.6-13.4)$ & $11.8(9.1-14.4)$ & $7.5(3.8-11.3)$ & $11.5(7.9-15.1)$ \\
Serum $\mathrm{Cu}, \mu \mathrm{g} / \mathrm{dl}$ & $56.9(46.8-67.1)$ & $51.3(42.2-60.4)$ & $52.0(39.5-64.4)$ & $50.0(23.8-76.3)$ & $50.9(27.8-74.0)$ \\
Urinary $\mathrm{Cu}, \mu \mathrm{g} / 24 \mathrm{~h}$ & $181.4(111.1-251.8)$ & $154.7(88.0-221.5)$ & $111.6(82.6-140.5)$ & $105.2(47.3-257.8)$ & $90.0(58.0-122.0)$ \\
\hline
\end{tabular}

Data are presented as mean $(95 \% \mathrm{CI})$. Laboratory norms: ceruloplasmin: $25-45 \mathrm{mg} / \mathrm{dl}$, serum copper: $70-140 \mu \mathrm{g} / \mathrm{dl}$, urinary copper: 0-50 $\mu \mathrm{g} / 24 \mathrm{~h}$ $N A$ not applicable

In the group of 43 ICs with neurological initial symptoms, we identified 24 ICs with 28 symptomatic siblings: 14 had neurological and 14 had hepatic manifestations at onset. Thirty-two siblings were presymptomatic at the time of diagnosis. This finding constitutes a $66 \%$ concordance rate of initial clinical presentation among neurological ICs and their symptomatic siblings. Although there were no differences between neurological ICs and their symptomatic siblings regarding the age of onset or the age of diagnosis, in this case ICs presented significantly lower ceruloplasmin $(p=0.004)$ and serum copper concentration $(p=0.001)$.

When all neurological ICs were compared with all symptomatic and presymptomatic siblings, we observed no differences regarding age at diagnosis; however, neurological ICs presented significantly lower ceruloplasmin and serum copper concentration levels (Table 2).

Genetic analysis

Among hepatic ICs and their symptomatic siblings with analyzed ATP7B mutations, the most frequent mutation was H1069Q (c.3207C>A), with an allelic frequency of
$77 \%$. In this group, 32 patients altogether had missense mutations in both ATP7B alleles, and eight patients $(20 \%)$ were compound heterozygotes possessing the H1069Q mutation on one allele and a severe (i.e., nonsense or frameshift) mutation on the second ATP7B allele.

In the group of neurological ICs and their symptomatic siblings with analyzed ATP7B mutations, the H1069Q mutation reached an allelic frequency of $73.5 \%$. Twenty-one patients altogether $(68 \%)$ had a missense mutation on both ATP7B alleles. Ten individuals (32\%) were compound heterozygotes possessing a missense mutation on one ATP7B allele and a severe mutation on the other allele (Table 3).

Aside from $\mathrm{H} 1069 \mathrm{Q}$, the most frequent missense mutations included T997M (c.2930T>C), T1220M (c.3659C >T), S653Y (c.1958C >A), and G988R (c.2962G>C). Among severe mutations, the T997M (c.2930T >C), T1220M (c.3659C >T), S653Y (c.1958C >A), and G988R (c.2962G>C) were identified.

Concordance rates and further comparisons were not evaluated because the numbers of patients were too small when patients were assigned to subgroups according to each carrier's mutation status.

Table 2 Clinical and biochemical characteristics of index cases (ICs) with neurological signs at onset and their siblings

\begin{tabular}{llllll}
\hline Group & $\begin{array}{l}\text { All neurological } \\
\text { ICs }\end{array}$ & All siblings of neurological ICs & Hepatic siblings & $\begin{array}{l}\text { Neurological } \\
\text { siblings }\end{array}$ & $\begin{array}{l}\text { Pre-symptomatic } \\
\text { siblings }\end{array}$ \\
\hline $\mathrm{N}$ & 43 & 60 & 14 & 14 & 32 \\
Age at onset, years & $25.3(23.3-27.2)$ & NA & $23.7(17.2-30.2)$ & $27.2(23.1-32.3)$ & NA \\
Age at diagnosis, years & $26.1(24.3-27.8)$ & $27.2(24.6-29.9)$ & $29.2(22.6-35.8)$ & $28.3(24.0-32.7)$ & $25.9(21.9-29.9)$ \\
Ceruloplasmin, $\mathrm{mg} / \mathrm{dl}$ & $10.7^{*}(8.8-12.6)$ & $16.8^{*}(14.8-18.9)$ & $17.0(11.7-22.3)$ & $17.6(12.9-22.2)$ & $16.1(13.4-18.8)$ \\
Serum $\mathrm{Cu}, \mu \mathrm{g} / \mathrm{dl}$ & $32.2^{* *}(25.1-39.3)$ & $48.8^{* *}(43.1-54.3)$ & $54.8(39.6-69.9)$ & $50.0(36.1-64.0)$ & $45.3(38.9-51.8)$ \\
Urinary $\mathrm{Cu}, \mu \mathrm{g} / 24 \mathrm{~h}$ & $126.6(96.4-156.8)$ & $164.5(123.5-205.5)$ & $126.2(70.6-$ & $116.8(77.6-$ & $156.1(68.4-$ \\
& & & $181.7)$ & $156.0)$ & $121.9)$ \\
\hline
\end{tabular}

Data are presented as mean $(95 \% \mathrm{CI})$. Laboratory norms: ceruloplasmin: $25-45 \mathrm{mg} / \mathrm{dl}$, serum copper: $70-140 \mu \mathrm{g} / \mathrm{dl}$, urinary copper: $0-50 \mu \mathrm{g} / 24 \mathrm{~h}$ $N A$ not applicable

${ }^{*} p<0.001 ; * * p<0.001$ 
Table 3 Mutation frequencies according to functional severity among index cases (ICs) and their symptomatic siblings

${ }^{\mathrm{a}}$ Frameshift and nonsense mutations are considered severe mutations

\begin{tabular}{llllll}
\hline Mutation & Hepatic ICs & $\begin{array}{l}\text { Siblings of } \\
\text { hepatic ICs }\end{array}$ & Neurological ICs & $\begin{array}{l}\text { Siblings of } \\
\text { neurological ICs }\end{array}$ & Total \\
\hline HQ/HQ & 12 & 12 & 8 & 10 & 42 \\
HQ/Missense or Missense/Missense & 4 & 4 & 1 & 2 & 11 \\
HQ/Severe or Missense/Severe & 3 & 5 & 5 & 5 & 18 \\
\hline
\end{tabular}

\section{Discussion}

Our data revealed an impressive $86 \%$ concordance rate of clinical symptoms between hepatic ICs and their symptomatic siblings at the time of disease onset, and a $66 \%$ concordance rate of clinical symptoms between neurological ICs and their siblings. These results suggest that members of the same family may have very similar phenotypic presentation of WD. These high concordance rates may reflect the influence of inherited genetic similarities (including, but not limited to, the ATP7B mutation) and environmental factors that are shared within the same family and influence affected siblings to a comparable degree and for a comparable period of time. Conversely, less than $100 \%$ concordance may reflect the influence of other non-shared environmental and genetic components, owing to complex individual differences.

There are other autosomal recessive disorders that lack any clear-cut genotype-phenotype correlations, in which other genetic and non-genetic factors are considered to have substantial phenotype-modifying effects (Scriver and Waters 1999; Burke 2003; Rankin et al. 2008). In WD, other genetic factors presumed to influence the phenotype include allele status and the mutations of methyltetrahydrofolate reductase (Gromadzka et al 2011), prion-related protein (PrP) (Merle et al 2006), interleukin-1 receptor antagonist (Gromadzka and Członkowska 2011), or apolipoprotein E genes (Schiefermeier et al 2000; Litwin et al 2012). Individual differences in hepatic copper metabolism, tolerance to copper toxicity, and allelic dominance mechanisms are considered as main determinants of intra-familial diversity in WD (Takeshita et al 2002).

Slightly higher concordance between hepatic ICs and their symptomatic siblings versus neurological ICs and their siblings can be partly explained by the primary principles of copper metabolism, since the liver is the first organ in which copper accumulates and is especially prone to damage caused by copper overload (Linder et al 1998).

Neurological presentation appears to be more complicated and less predictable, given that there are more complex interactions between copper and ceruloplasmin and the central nervous system. First, copper serves as a cofactor and a modulator of enzymes that are crucial for brain homeostasis, such as superoxide dismutase and dopamine hydroxylase. Copper is also centrally involved in iron transport (Cox and Moore 2002) and myelination processes (Prodan et al 2002). Additionally, brain-specific amyloid precursor protein and
PrP are copper-binding, copper-dependent proteins that have important roles in neurodegeneration (Multhaup et al 1996; Millhauser 2004). Ceruloplasmin itself is involved in the transport of other metal ions and possesses very strong antioxidant properties, such as ferroxidase activity (Gutteridge 1978). Therefore, reduced ceruloplasmin levels may reflect an increased level of oxidative stress. In conclusion, high intrafamilial concordance rates of clinical and biochemical presentation of WD revealed among siblings shall be a premise for further research regarding the influence of epigenetic, environmental, and other genetic factors.

Acknowledgments This article was prepared within the frame of statutory research activities of the Institute of Psychiatry and Neurology, Warsaw, Poland. All financial involvement (e.g., employment, consultancies, honoraria, stock ownership or options, grants or patents receiving or pending, royalties) with any organization or entity with a financial interest in or financial conflict with the subject matter or materials discussed in this article are completely disclosed.

\section{Conflict of interest None}

Open Access This article is distributed under the terms of the Creative Commons Attribution License which permits any use, distribution, and reproduction in any medium, provided the original author(s) and the source are credited.

\section{References}

Behari M, Pardasani V (2010) Genetics of Wilsons disease. Parkinsonism Relat Disord 16:639-644

Burke W (2003) Genomics as a probe for disease biology. N Engl J Med 349:969-974

Coffey AJ, Durkie M, Hague S et al (2013) A genetic study of Wilson's disease in the United Kingdom. Brain 136:1476-1487

Cox DW, Moore SDP (2002) Copper transporting P-type ATPases and human disease. J Bioenerg Biomembr 34:333-338

Członkowska A, Gromadzka G, Chabik G (2009) Monozygotic female twins discordant for phenotype of Wilson's disease. Mov Disord 24:1066-1088

Das SK, Ray K (2006) Wilson's disease: an update. Nat Clin Pract Neurol 2(9):482-493

Deguti MM, Genschel J, Cancado ELR et al (2004) Wilson disease: novel mutations in the ATP7B gene and clinical correlation in Brazilian patients. Hum Mutat 23:398

Ferenci P, Caca K, Loudianos G et al (2003) Diagnosis and phenotypic classification of Wilson disease. Liver Int 23:139-142

Gromadzka G, Członkowska A (2011) Influence of IL-1RN intron 2 variable number of tandem repeats (VNTR) polymorphism on the age at onset of neuropsychiatric symptoms in Wilson's disease. Int J Neurosci 121:8-15 
Gromadzka G, Schmidt HH, Genschel J et al (2005) Frameshift and nonsense mutations in the gene for ATPase7B are associated with severe impairment of copper metabolism and with an early clinical manifestation of Wilson's disease. Clin Genet 68:524-532

Gromadzka G, Schmidt HH, Genschel J et al (2006) p.H1069Q mutation in ATP7B and biochemical parameters of copper metabolism and clinical manifestation of Wilson's disease. Mov Disord 21:245-248

Gromadzka G, Rudnicka M, Chabik G, Przybyłkowski A, Członkowska A (2011) Genetic variability in the methylenetetrahydrofolate reductase gene (MTHFR) affects clinical expression of Wilson's diseases. J Hepatol 55:913-919

Gupta A, Chattopadhyay I, Dey S et al (2007) Molecular pathogenesis of Wilson disease among Indians: a perspective on mutation spectrum in ATP7B gene, prevalent defects, clinical heterogeneity and implication towards diagnosis. Cell Mol Neurobiol 27(8):1023-1033

Gutteridge JMC (1978) Ceruloplasmin: a plasma protein, enzyme and anti-oxidant. Ann Clin Biochem 15:293-296

Ha-Hao D, Hefter H, Stremmel W et al (1998) His1069Gln and six novel Wilson disease mutations: analysis of relevance for early diagnosis and phenotype. Eur J Hum Genet 6:616-623

Houwen RH, Juyn J, Hoogenraad TU, Ploos van Amstel JK, Berger R (1995) H714Q mutation in Wilson disease is associated with late, neurological presentation. J Med Genet 32:480-482

Linder MC, Wooten L, Cerveza P, Cotton S, Shulze R, Lomeli N (1998) Copper transport. Am J Clin Nutr 67:965-971

Litwin T, Członkowska A (2013) Wilson disease-factors affecting clinical presentation. Neurol Neurochir Pol 47:161-169

Litwin T, Gromadzka G, Członkowska A (2012) Apolipoprotein E gene (APOE) genotype in Wilson's disease: impact on clinical presentation. Parkinsonism Relat Disord 18:367-369

McGue M (1992) When assessing twin concordance, use the probandwise not the pairwise rate. Schizophr Bull 18:171-176

Merle U, Stremmel W, Gesner R (2006) Influence of homozygosity for methionine at codon 129 of the human prion gene on the onset of neurological and hepatic symptoms in Wilson's disease. Arch Neurol 63:982-985

Millhauser GL (2004) Copper binding in the prion protein. Acc Chem Res 37:79-85
Multhaup G, Schlicksupp A, Hesse L et al (1996) The amyloid precursor protein of Alzheimer's disease in the reduction of copper(II) to copper(I). Science 271:1406-1409

Olsson C, Waldenström E, Westermark K, Landegren U, Syvänen AC (2000) Determination of the frequencies of ten allelic variants of the Wilson disease gene (ATP7B), in pooled DNA samples. Eur J Hum Genet 8:933-938

Prodan CI, Holland NR, Wisdom PJ, Burstein SA, Bottomley SS (2002) CNS demyelination associated with copper deficiency and hyperzincemia. Neurology 59:1453-1456

Rankin J, Auer-Grumbach M, Bagg W et al. (2008) Extreme phenotypic diversity and nonpenetrance in families with the LMNA gene mutation R644C. Am J Med Genet 146:1530-1542.

Ravin HA (1961) An improved colorimetric assay of ceruloplasmin. J Lab Clin Med 61:161-168

Santhosh S, Shaji RV, Eapen CE et al (2008) Genotype phenotype correlation in Wilson's disease within families - a report on four south Indian families. World J Gastroenterol 14:4672-4676

Scheinberg IH, Sternlieb I (1984) Wilson's disease. In: Lloyd H, Smith J (eds) Major problems in internal medicine. Saunders, Philadelphia, p 23

Schiefermeier M, Kollegger H, Madl C et al (2000) The impact of, apolipoprotein $\mathrm{E}$ genotypes on age at onset of, symptoms and phenotypic expression in Wilson's disease. Brain 123:585-590

Scriver CR, Waters PJ (1999) Monogenic traits are not simple: lessons from phenylketonuria. Trends Genet 15:267-272

Smith C (1974) Concordance in twins: methods and interpretation. Am J Hum Genet 26:454-466

Stapelbroek JM, Bollen CW, van Amstel JK et al (2004) The H1069Q mutation in ATP7B is associated with late and neurologic presentation in Wilson disease: results of a meta-analysis. J Hepatol 41:758-763

Takeshita Y, Shimizu N, Yamaguchi Y et al (2002) Two families with Wilson disease in which siblings showed different phenotypes. J Hum Genet 47:543-547

Vrabelova S, Letocha O, Borsky M, Kozak L (2005) Mutation analysis of the ATP7B gene and genotype/phenotype correlation in 227 patients with Wilson disease. Mol Genet Metab 86:277-285 